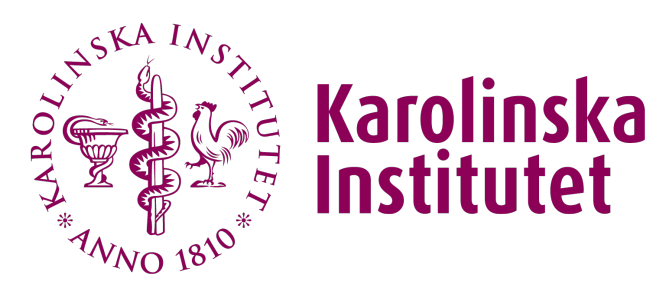

Karolinska Institutet

http://openarchive.ki.se

This is a Peer Reviewed Accepted version of the following article, accepted for publication in Nature Cell Biology.

\title{
Reticular adhesions are a distinct class of cell-matrix adhesions that mediate attachment during mitosis
}

Lock, John G; Jones, Mattew C; Askari, Janet A; Gong, Xiaowei; Oddone, Anna; Olofsson, Helene; Göransson, Sara; Lakadamyali, Melike; Humphries, Martin J; Strömblad, Staffan

Nat Cell Biol. 2018 Nov;20(11):1290-1302.

http://doi.org/10.1038/s41556-018-0220-2

http://hdl.handle.net/10616/46640

If not otherwise stated by the Publisher's Terms and conditions, the manuscript is deposited under the terms of the Creative Commons Attribution-NonCommercial-NoDerivatives License (http://creativecommons.org/licenses/by-nc-nd/4.0/), which permits non-commercial re-use, distribution, and reproduction in any medium, provided the original work is properly cited, and is not altered, transformed, or built upon in any way. 


\section{(1) \\ Karolinska \\ Institutet}

This is a post-peer-review, pre-copyedit version of an article published in Nature Cell Biology.

The final authenticated version is available online at:

http:/ / dx.doi.org/10.1038/s41556-018-0220-2

This paper has been peer-reviewed but does not include the

final publisher proof-corrections or journal pagination.

Citation for the published paper:

Lock JG, Jones MC, Askari JA, Gong X, Oddone A, Olofsson H, Göransson S, Lakadamyali M, Humphries MJ, Strömblad S.

Reticular adhesions are a distinct class of cell-matrix adhesions that mediate attachment during mitosis.

Nat Cell Biol. 2018 Nov;20(11):1290-1302

Access to the published version may require subscription.

Published with permission from: Springer Nature 

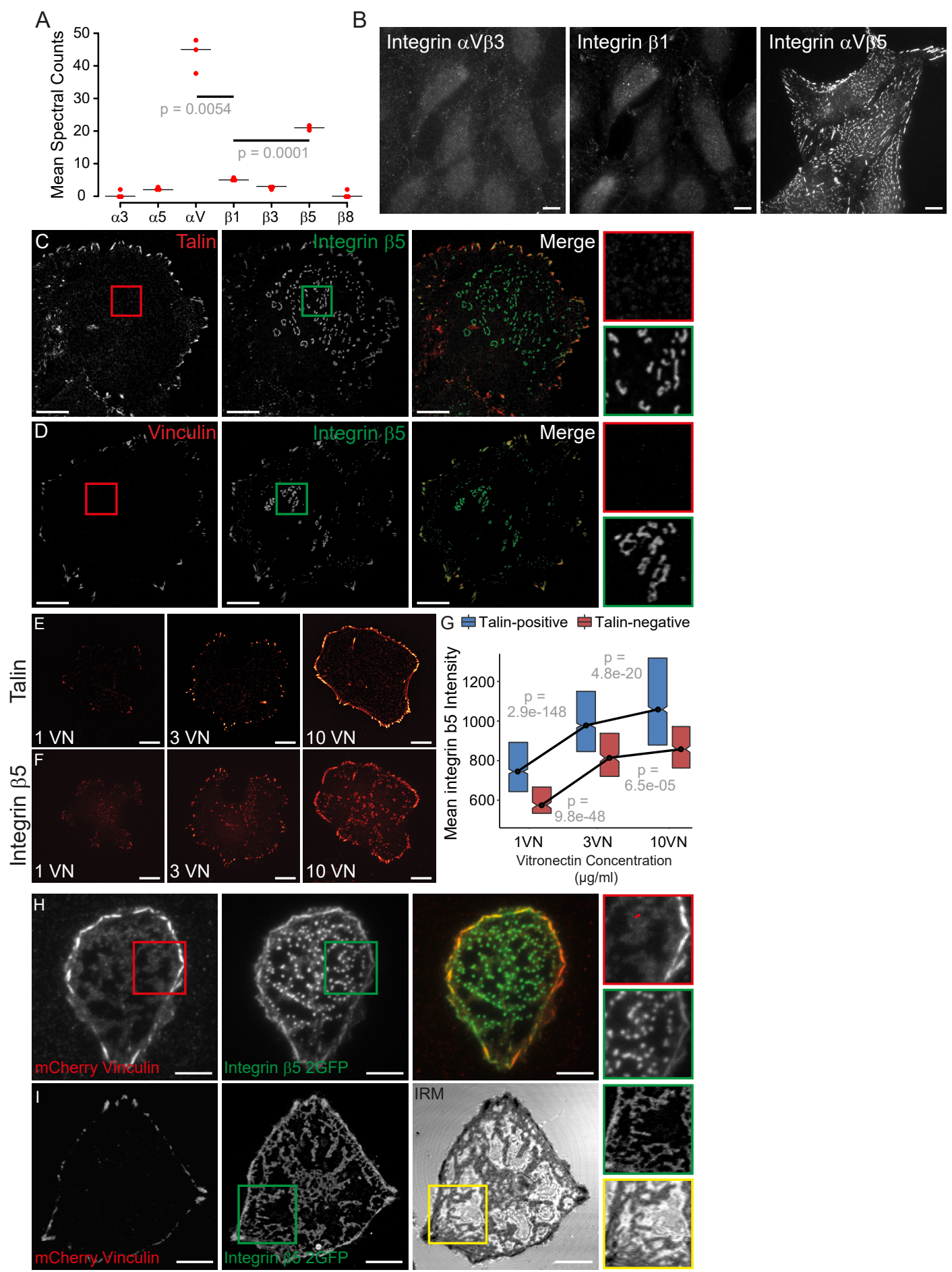

Fig. 1 
A B

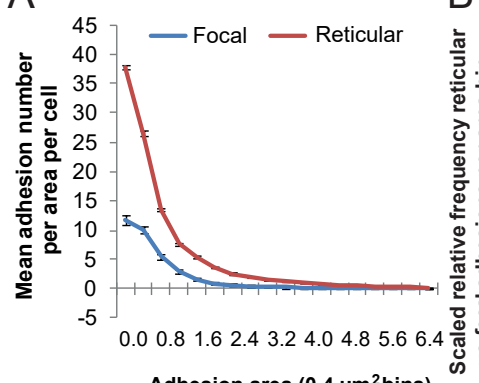

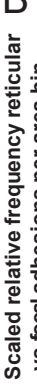

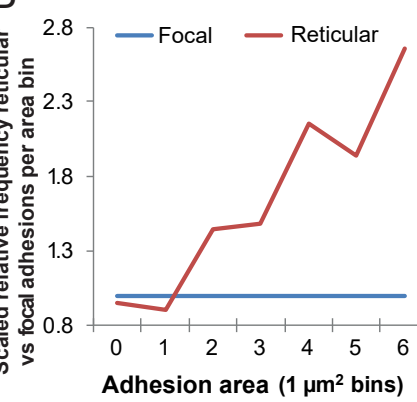

C

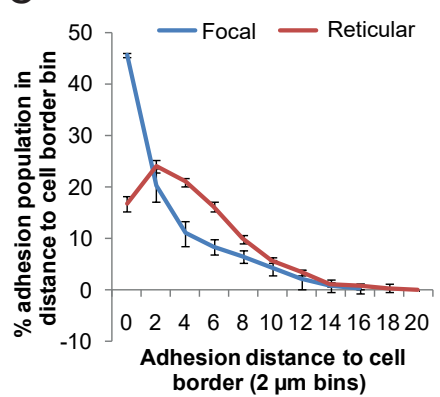

D

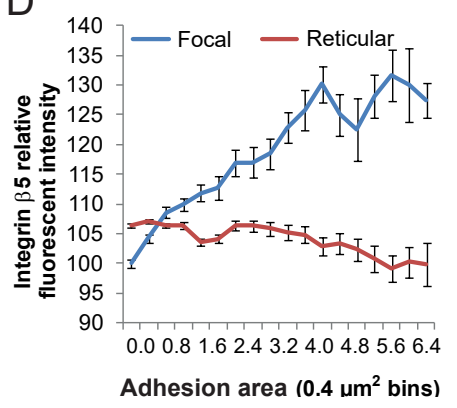

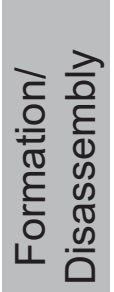
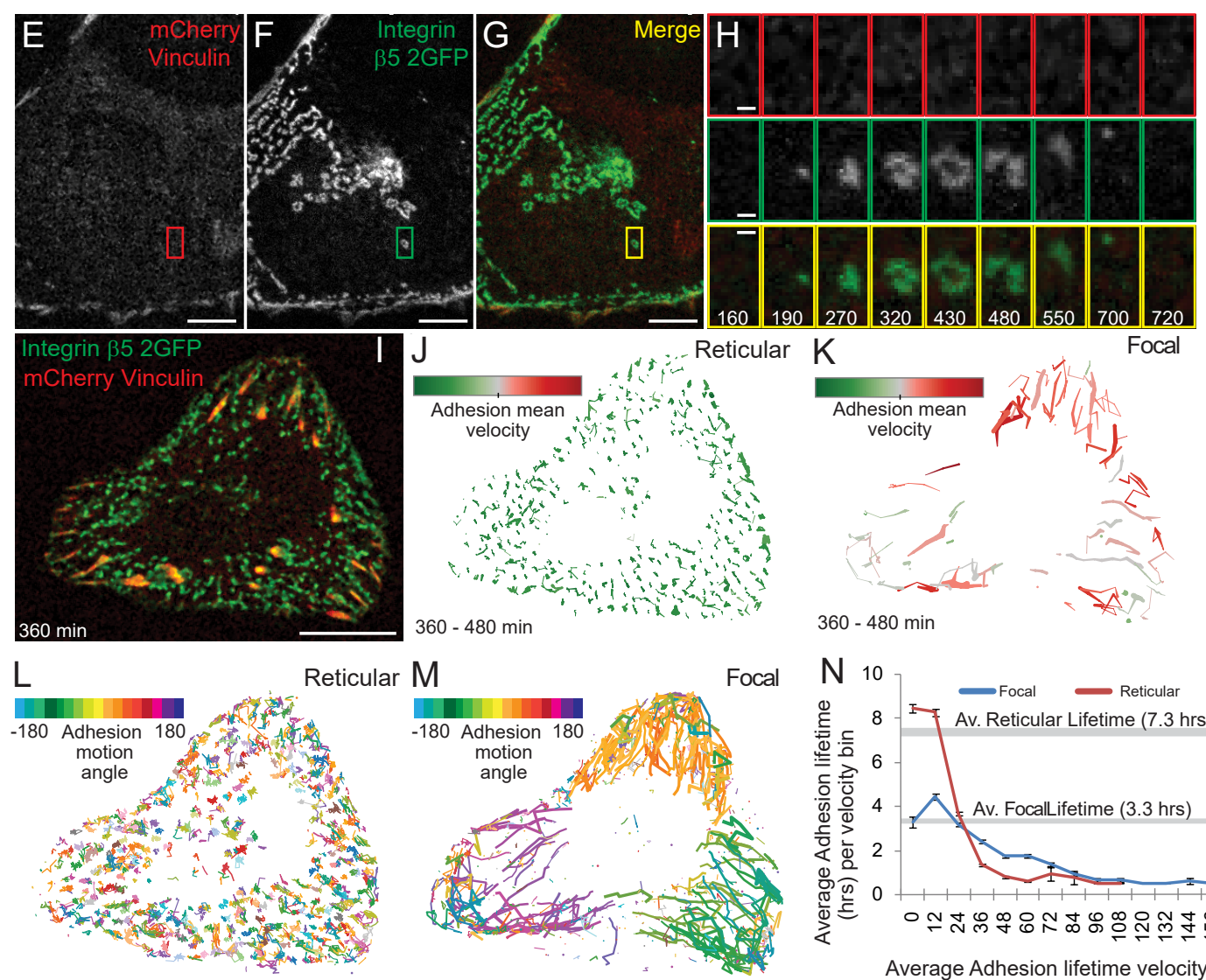

\section{$\mathrm{M}$}

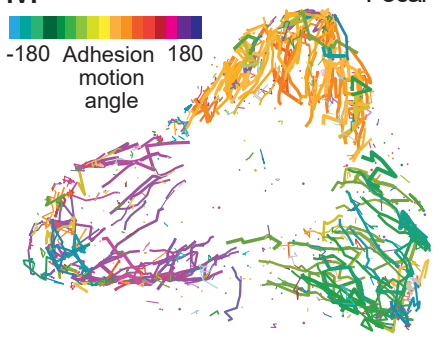

Focal

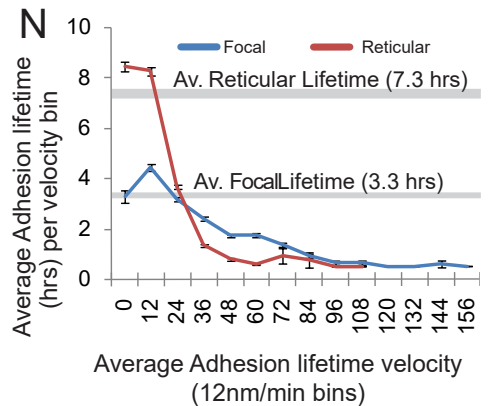

Fig. 2 


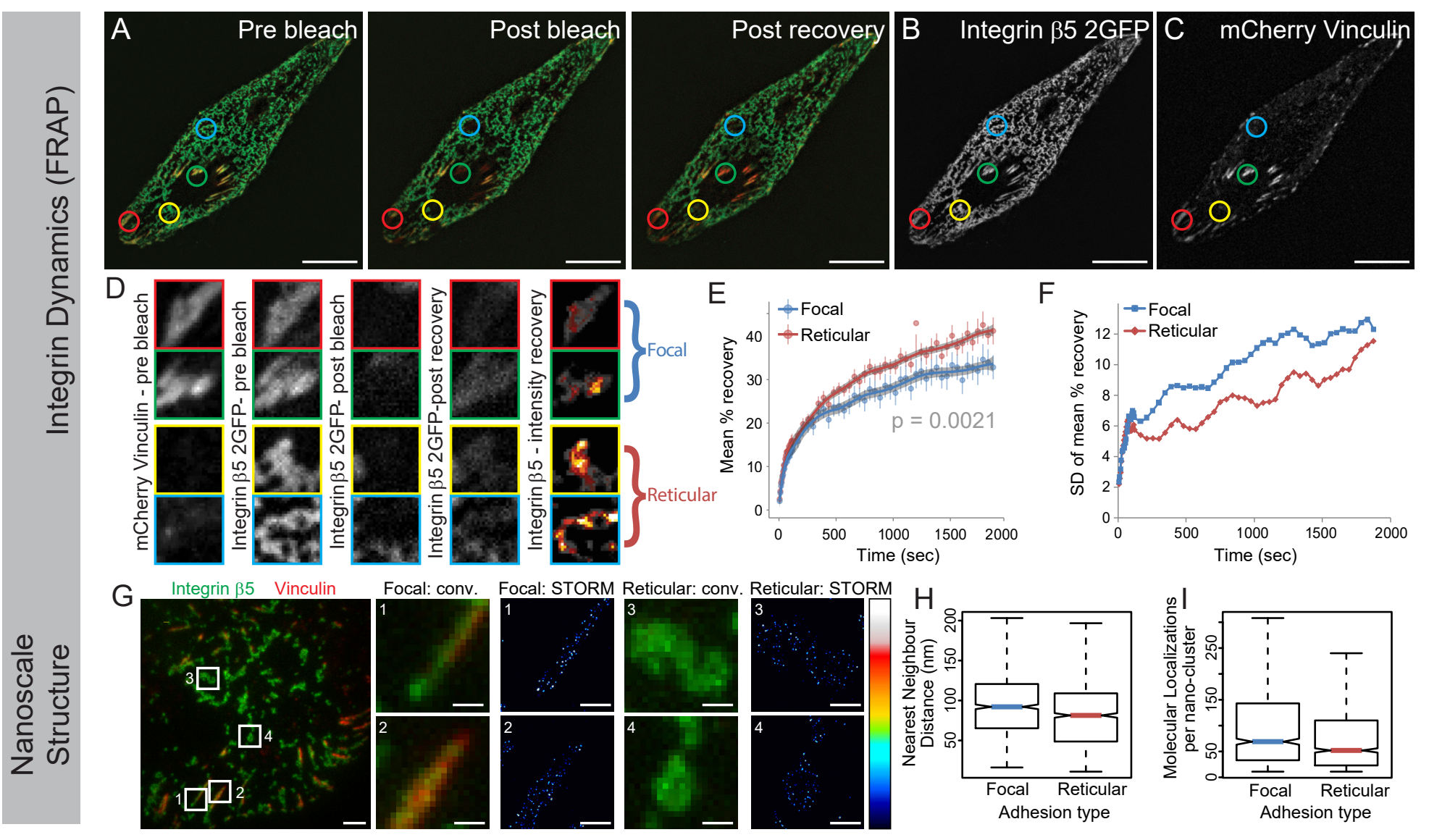

Fig. 3 
A

B

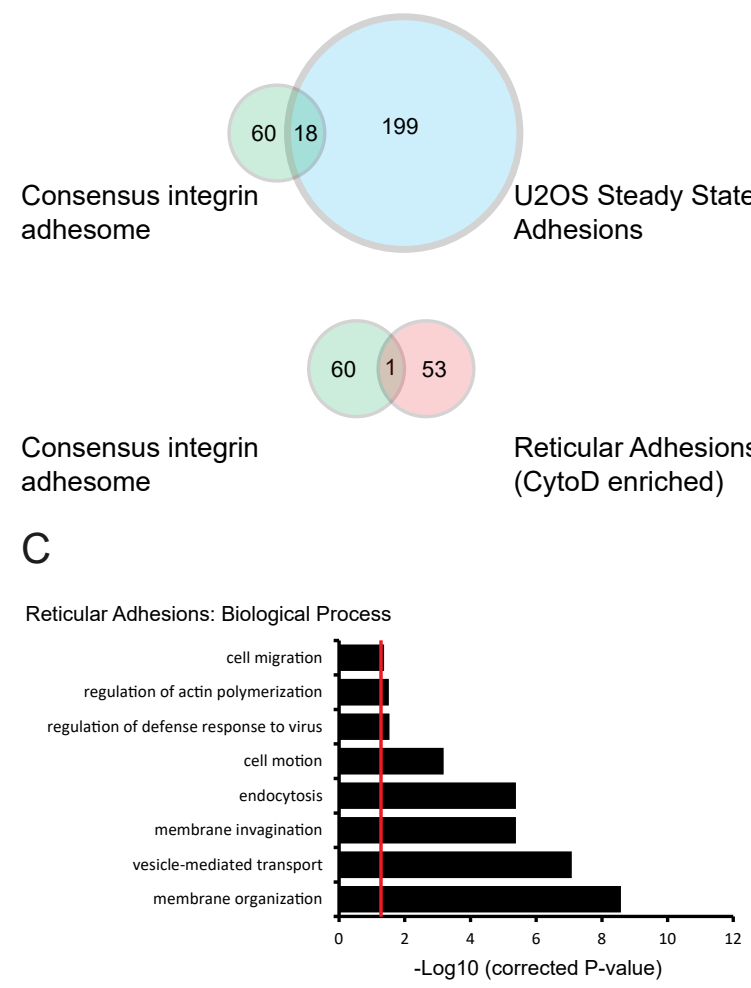

$\mathrm{D}$

Reticular Adhesions: KEGG Pathway

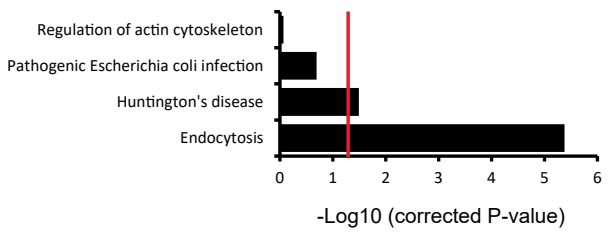
Direct binding of PI4,5P2 $\bigcirc \begin{gathered}\text { Indirect PI4,5P2 association } \\ \text { (via direct binding partner) }\end{gathered} \overbrace{\text { association }}^{\text {No clear PI4,5P2 }}$ association

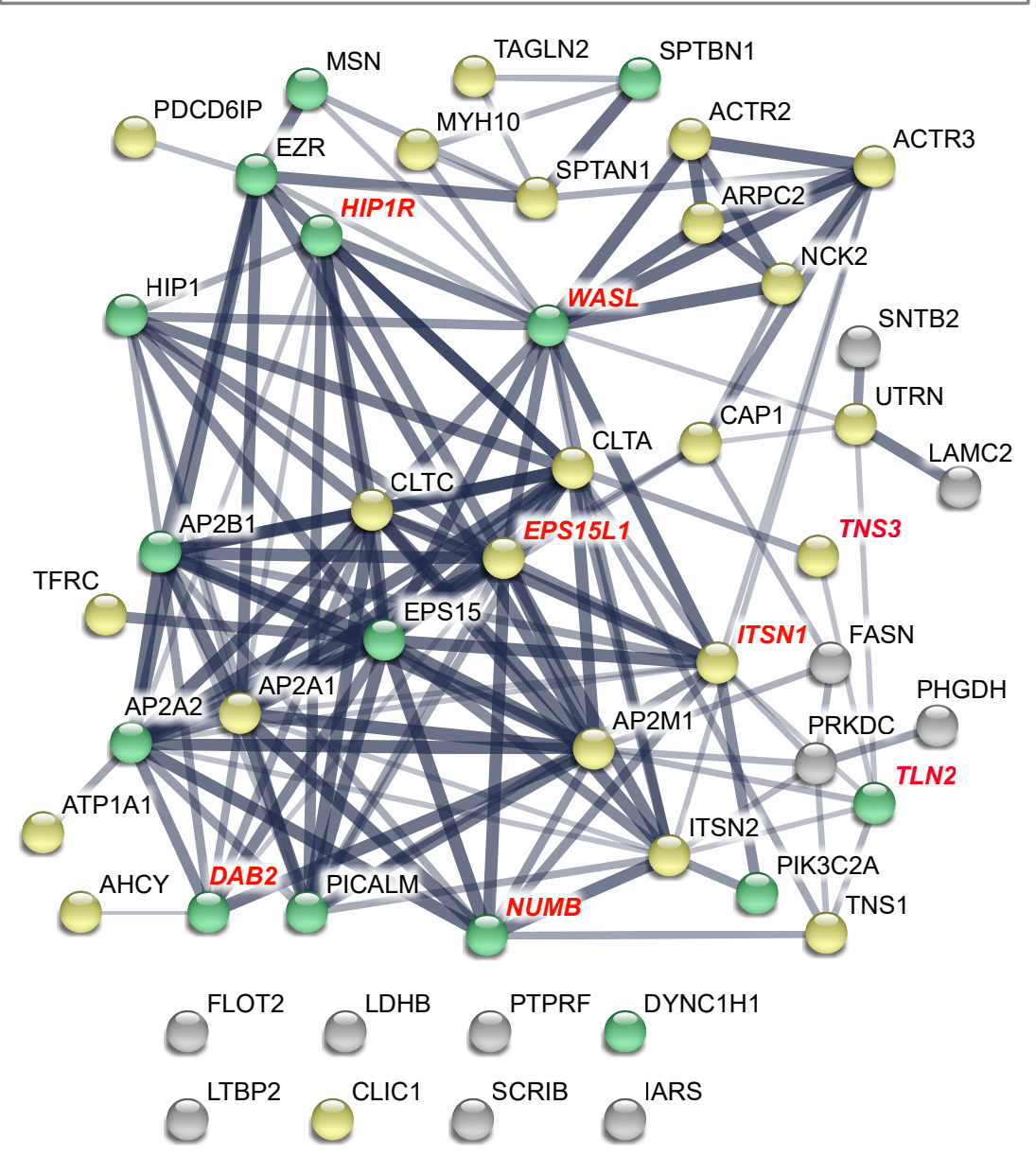

$\mathrm{E}$
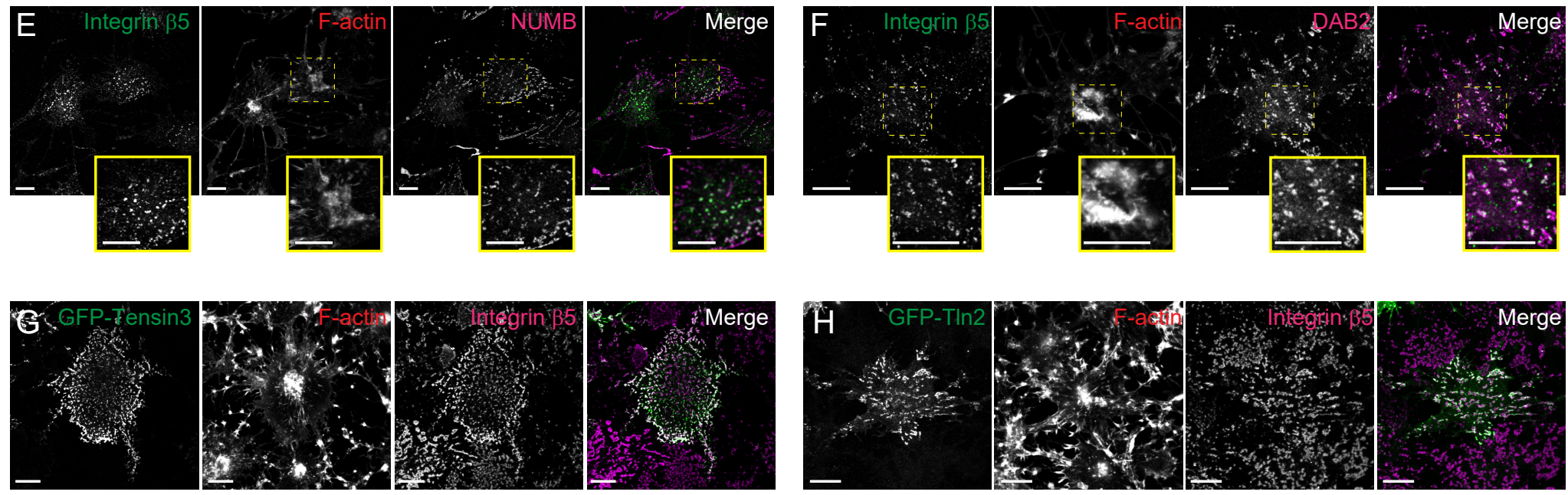

Fig. 5 
A

F-actin

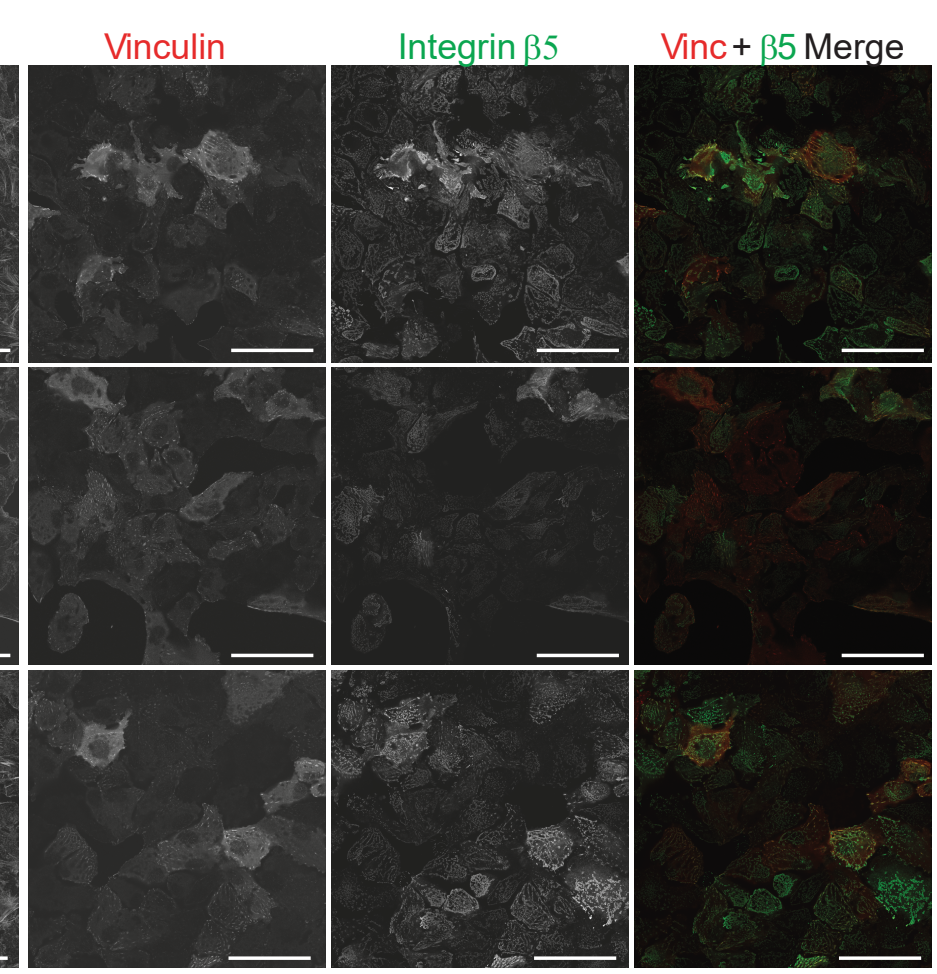

B

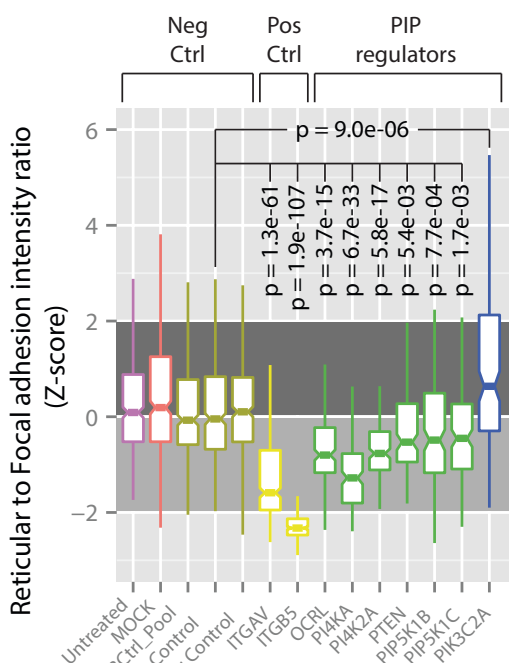

Treatment (siRNA)

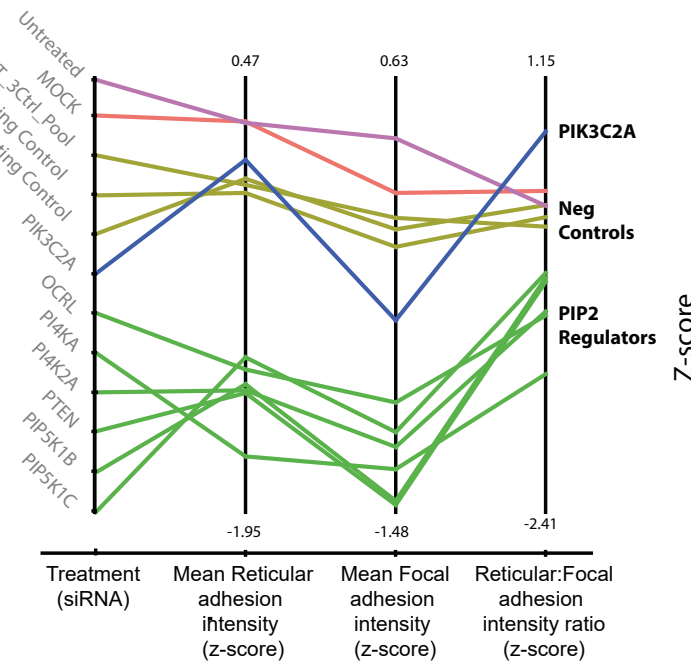

D

Mean Reticular Mean Focal Reticular:Focal adhesion adhesion adhesion $\begin{array}{llc}\text { intensity } & \text { intensity } & \text { intensity ratio } \\ \text { (z-score) } & \text { (z-score) } & \text { (z-score) }\end{array}$

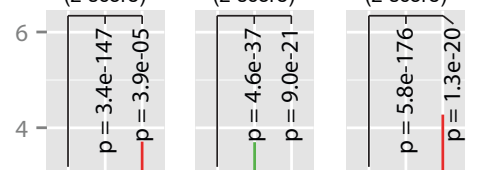

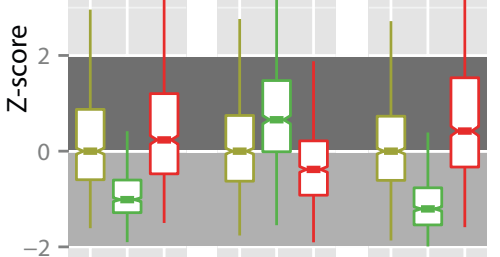

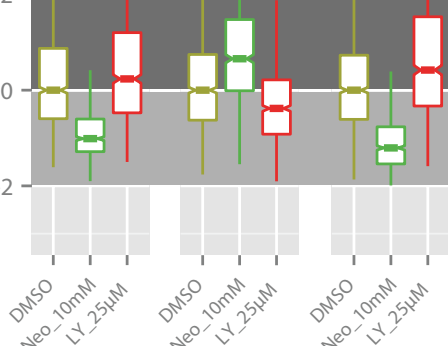

Treatment (Inhibitor)

Fig. 6 

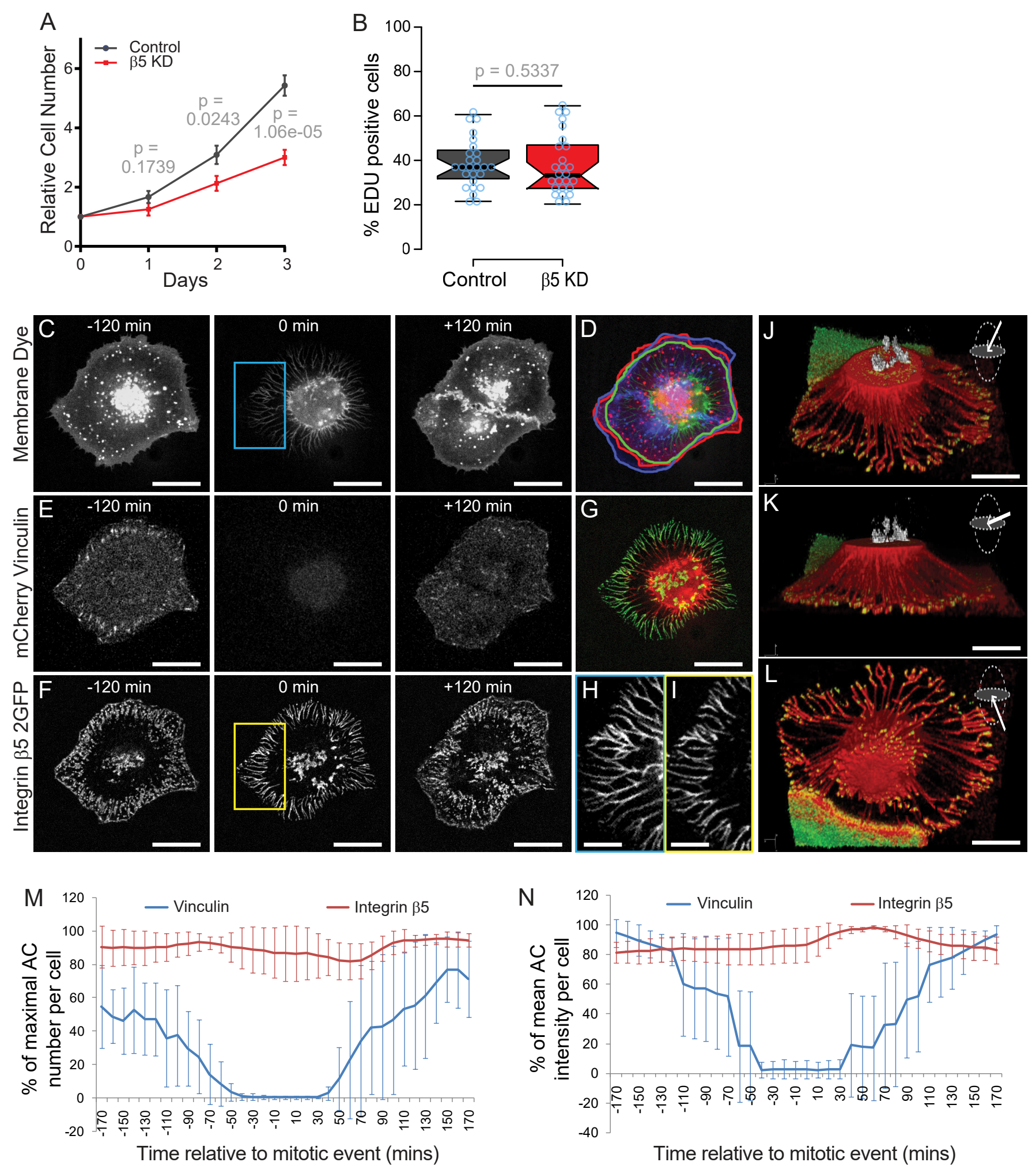

Time relative to mitotic event (mins)

Fig. 7 

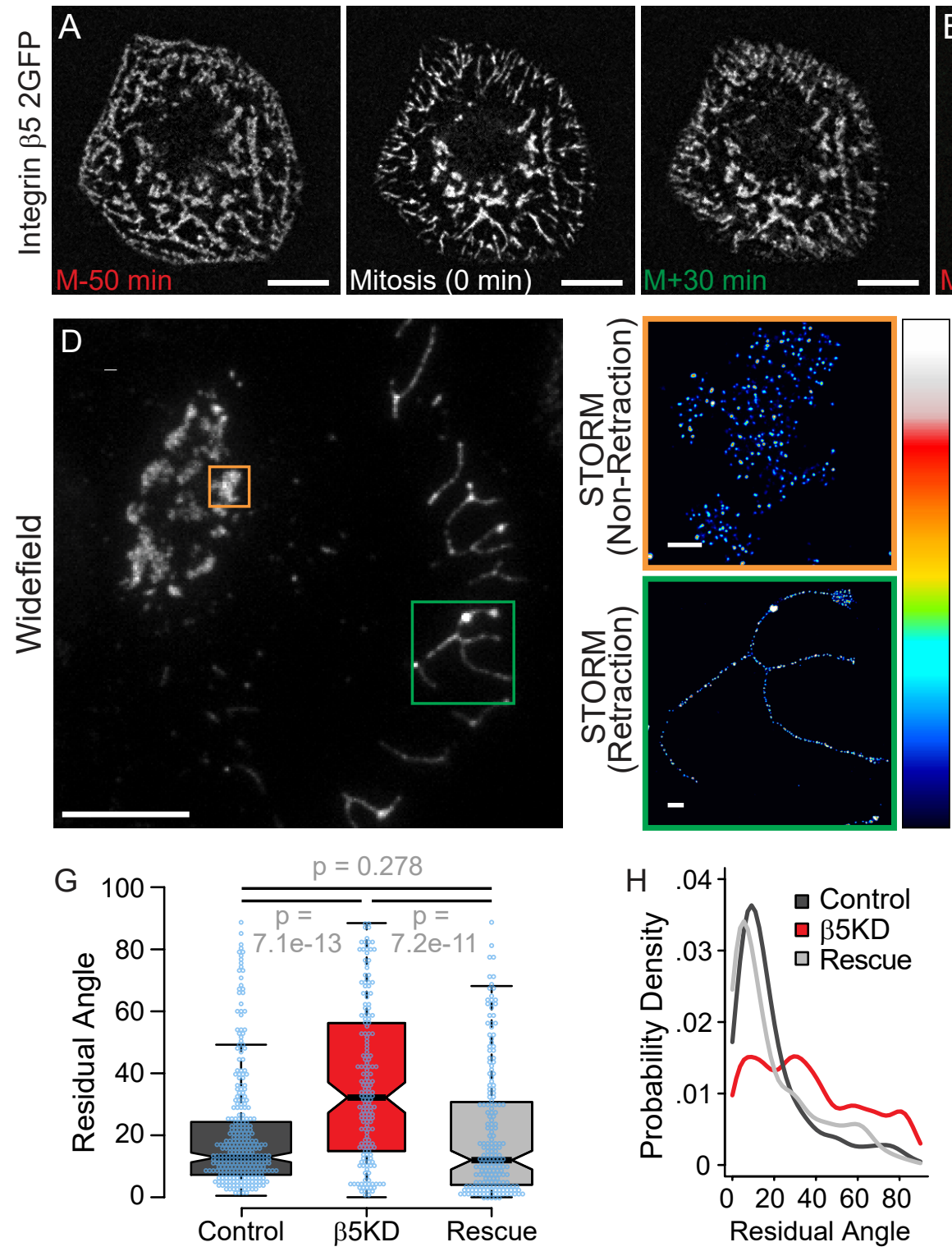
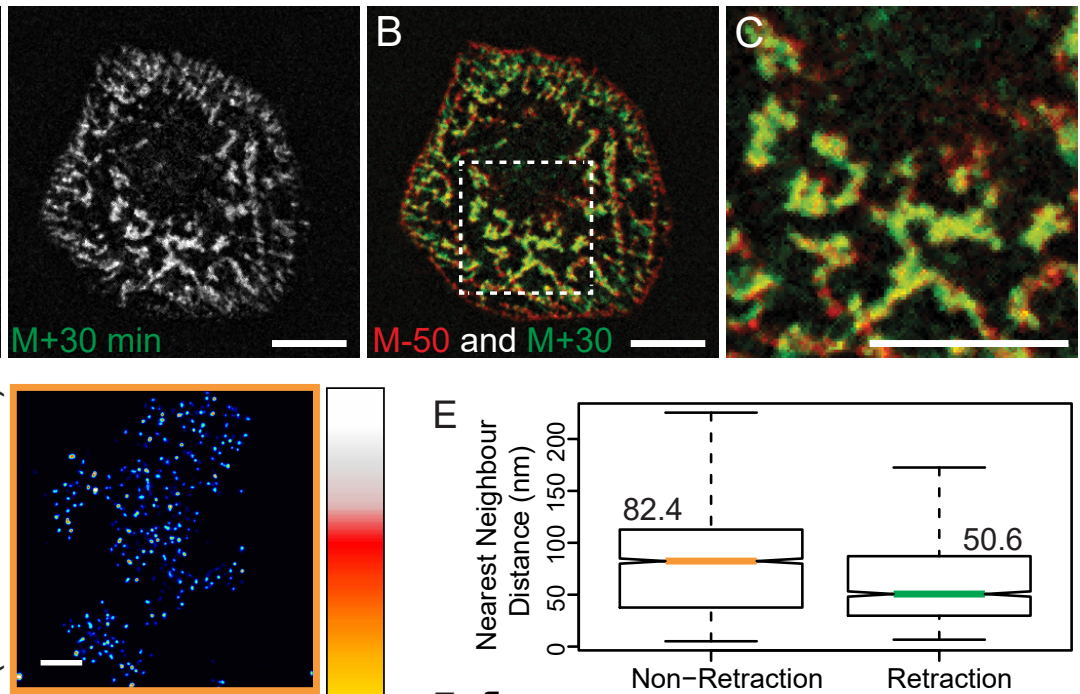

$F$
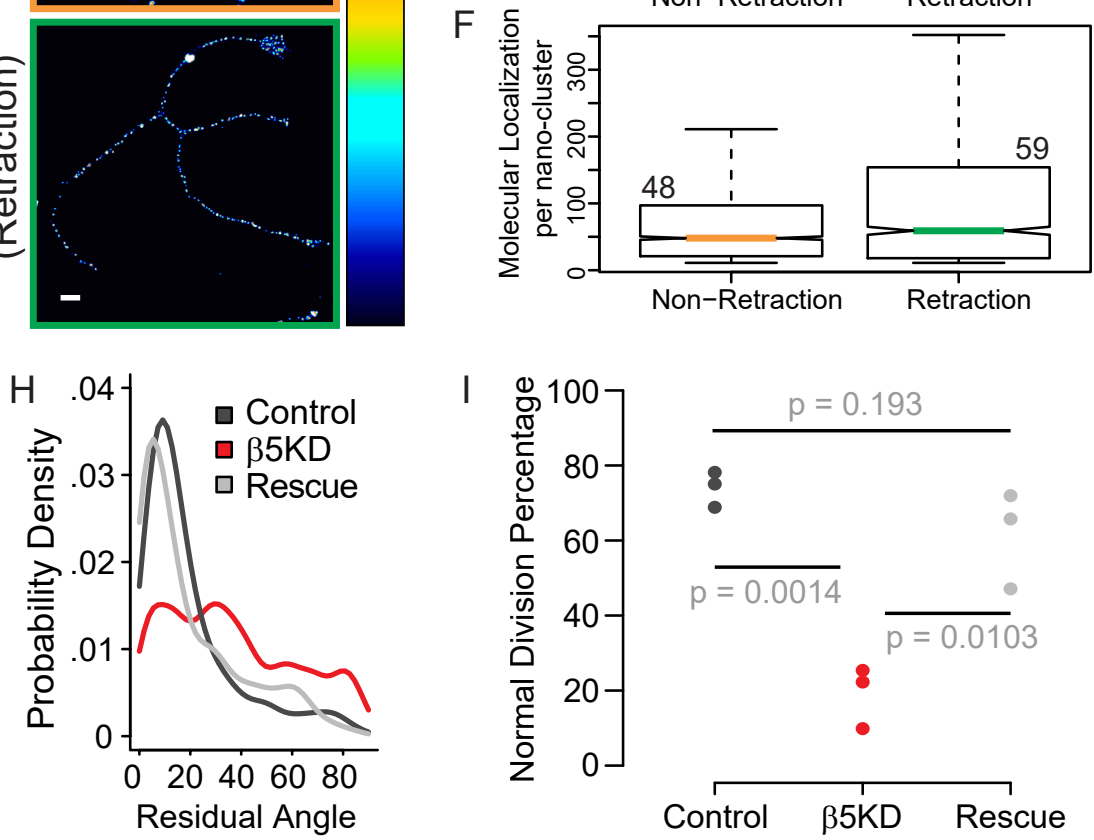

Fig. 8 